\title{
LA CONVENCIÓN SOBRE PREVENCIÓN Y CASTIGO DE DELITOS CONTRA PERSONAS INTERNACIONALMENTE PROTEGIDAS, INCLUIDOS LOS AGENTES DIPLOMÁTICOS (NUEVA YORK, 1973): ANÁLISIS Y PERSPECTIVAS ACTUALES DE APLICACIÓN
}

\author{
Elena CONDE PÉREZ \\ Profesora Titular de Derecho \\ Internacional Público. UCM. \\ conde@der.cum.es
}

\begin{abstract}
RESUMEN
Transcurridos casi cuarenta años desde la adopción de la Convención de las Naciones Unidas sobre prevención y castigo de delitos contra personas internacionalmente protegidas, incluidos los agentes diplomáticos (Nueva York, 1973), se impone la reflexión acerca de su aplicabilidad a supuestos actuales en un contexto de acción global contra el terrorismo internacional. Las normas del Convenio, especialmente la regla aut dedere aut indicare, sirven de base para analizar la oportunidad y aplicación actual del tratado que, en casos recientes, como el del asesinato del ex primer ministro libanés R. Hariri, ha sido contemplado en el marco de acción del Consejo de Seguridad de las Naciones Unidas.
\end{abstract}

Palabras clave: Derecho diplomático, terrorismo, extradición, aut dedere aut indicare, agentes diplomáticos, personas internacionalmente protegidas.

\section{ABSTRACT}

After almost 40 years since the adoption of the United Nations Convention on the Prevention and Punishment of Crimes against Internationally Protected Persons, including Diplomatic Agents (New York, 1973), the reflection on their applicability to current assumptions in the context of global action against international terrorism is required. The rules of the Convention, especially the rule on aut dedere aut iudicare, provide a basis for analyzing the current timing and implementation of the treaty which, in recent cases, such as the assassination of former Lebanese Prime Minister R. Hariri, has been considered within the scope of action of the United Nations Security Council.

Keywords: Diplomatic Law, terrorism, extradition, aut dedere aut iudicare, diplomatic agents, internationally protected persons. 


\section{ZUSAMMENFASSUNG}

Nachdem nun fast 40 Jahre seit der Verabschiedung des UN-Übereinkommens über die Verbütung, Verfolgung und Bestrafung von Straftaten gegen völkerrechtlich geschützte Personen, einschließlich Diplomaten, (New York, 1973):vergangen sind, drängt sich eine Betrachtung über die Anwendbarkeit in aktuellen Fällen und im Kontext von globalem Einsatz gegen den internationalen Terrorismus auf. Die Rechtsnormen der Übereinkunft, besonders die Regelung «aut dedere aut iudicare», dienen als Grundlage, um die Möglichkeit der Durchführung und die derzeitige Anwendung des Übereinkommens zu überprüfen. Verwiesen sei hierbei auf die vor ein paar Jabren stattgefundene Ermordung des ehemaligen libanesischen Premierministers R. Hariri, der im Aktionsplan des UN-Sicherbeitsrats berïcksichtigt wurde.

Schlüsselwörter: Diplomatenrecht, Terrorismus, aut dedere aut iudicare, Diplomaten, völkerrechtlich geschützte Personen.

SUMARIO: I. INTRODUCCIÓN.-II. HISTORIA LEGISLATIVA DE LA CONVENCIÓN SOBRE PREVENCIÓN Y CASTIGO DE DELITOS CONTRA PERSONAS INTERNACIONALMENTE PROTEGIDAS, INCLUIDOS LOS AGENTES DIPLOMÁTICOS (NUEVA YORK, 1973).-1. Antecedentes.-2. Del proyecto de artículos de la CDI a la adopción de la Convención por la Asamblea General.-III. EL ÁMBITO DE APLICACIÓN MATERIAL DE LA CONVENCIÓN DE NUEVA YORK DE 1973.-1. Ámbito de aplicación rationae personae.-2. Un aspecto problemático: la tipificación de los delitos punibles.IV. LA REGLA AUT DEDERE AUT IUDICARE Y EL MÁS AMPLIO DEBER DE COOPERACIÓN PENAL INTERNACIONAL: SUPERACIÓN DEL SISTEMA PREVISTO EN LA CONVENCIÓN.-1. Las reglas contenidas en los arts. 3 a 11 de la Convención.-2. Los tratados de extradición, fundamento y superación del modelo clásico.- - V. LA ACCIÓN DE LAS NACIONES UNIDAS EN LA LUCHA CONTRA LOS ATENTADOS TERRORISTAS COMETIDOS CONTRA PERSONAS INTERNACIONALMENTE PROTEGIDAS: OTRO EJEMPLO DE SUPERACIÓN DEL MODELO CONVENCIONAL. ESPECIAL REFERENCIA AL TRIBUNAL ESPECIAL PARA EL LÍBANO.-VI. CONCLUSIONES.

\section{INTRODUCCIÓN}

Tras la adopción de la Convención de Viena sobre relaciones diplomáticas de 1961 y de la Convención de Viena sobre relaciones consulares de 1963, se sucedieron los actos violentos contra «personas internacionalmente protegidas», en particular, contra agentes diplomáticos y misiones diplomáticas ${ }^{1}$, lo que explica la urgencia con que se negoció la Conven-

\footnotetext{
${ }^{1}$ Entre 1947 y 1967 al menos trece personas internacionalmente protegidas resultaron muertas como consecuencia de estos actos violentos. Vid. la pormenorizada relación de
} 
ción sobre prevención y castigo de delitos contra personas internacionalmente protegidas, incluidos los agentes diplomáticos, y su rápida entrada en vigor, que tuvo lugar el 20 de febrero de 1977. Los grupos violentos adivinaron la repercusión mediática que tendrían los actos perpetrados contra las personas internacionalmente protegidas, que se convirtieron así en uno de los blancos preferidos de aquéllos, como moneda de cambio para la consecución de sus objetivos.

Ciertamente la Convención objeto de este estudio no acabó con los atentados contra las personas internacionalmente protegidas y sus dependencias, pues, de hecho, uno de los acontecimientos que más páginas ha generado para el estudio de diversos aspectos del Derecho internacional se produciría poco después de la entrada en vigor de la Convención, me estoy refiriendo al asunto de los rehenes norteamericanos en Teherán (Estados Unidos de América c. República Islámica de Irán $)^{2}$, en el que «Estados Unidos sostuvo ante el Tribunal Internacional de Justicia que tolerando, alentando, adoptando y esforzándose en explotar y absteniéndose de prevenir y reprimir la acción de los militantes que se habían apoderado de los edificios diplomáticos y consulares norteamericanos, reteniendo en ellos a los rehenes, Irán había violado sus obligaciones internacionales, y más precisamente:

- Las Convenciones de Viena de 18 de abril de 1961 y de 24 de abril de 1963 sobre relaciones diplomáticas y consulares.

sucesos violentos que en los años anteriores a la adopción de la Convención sobre prevención y castigo de delitos contra personas internacionalmente protegidas recoge M. TÖKEY, «Fight against terrorism in the light of Convention on the Prevention and Punishment of Crimes against Internationally Protected Persons, including Diplomatic agents», Miskolc Journal of International Law, núm. 3, vol. 2, 2005, pp. 54-58. Vid., asimismo, E. DENZA, Diplomatic Law. Commentary on the Vienna Convention on Diplomatic Relations, 2." ed., Oxford University Press, 2008, pp. 212-220.

A. B. Green recoge, sin ánimo de exhaustividad, 23 asaltos contra personas internacionalmente protegidas - fundamentalmente, secuestros de personal diplomático- entre 1970 y 1971. Vid. A. B. GreEn, «Convention on the Prevention and Punishment of Crimes Against Diplomatic Agents and Other Internationally Protected Persons: An Analysis», Virginia Journal of International Law, vol. 14, 1973-1974, pp. 704-705, nota 5.

${ }_{2}$ CIJ Recueil, 1980, en http://www.icj-cij.org/docket/files/64/6291.pdf.

Existe amplísima bibliografía sobre este asunto, vid., entre otros muchos, M. P. ANDRÉs SÁenz de SANTA María, «La crisis de la inviolabilidad de las misiones diplomáticas: una perspectiva estructural de análisis», Revista de Estudios Internacionales, núm. 2, vol. 2, 1981, pp. 261-303; A. JeFFERY, «The American Hostages in Tehran: The ICJ and the Legality of Rescue Missions», International and Comparative Law Quarterly, 1981, pp. 717-729; K. Grzybowski, «The Regime of Diplomacy and the Tehran Hostages», International and Comparative Law Quarterly, 1981, pp. 42-58. 
- El Tratado de amistad, comercio y derechos consulares de 15 de agosto de 1955 entre Estados Unidos e Irán.

- La Convención de las Naciones Unidas de 14 de diciembre de 1973 sobre prevención y castigo de delitos contra personas internacionalmente protegidas, incluidos los agentes diplomáticos» ${ }^{3}$.

El leit motif de la Convención objeto de este análisis, que consta de 20 artículos ${ }^{4}$, consiste en que los presuntos responsables de los atentados contra personas internacionalmente protegidas, incluidos los agentes diplomáticos, sean extraditados o juzgados. Es decir, la Convención, sobre la base de estos actos, trata de dar juego a la cláusula aut dedere aut iudicare. Asimismo, los actos delictivos tipificados en la Convención (art. 2.1), incluyendo la amenaza, la tentativa y la complicidad en la comisión de los mismos, deben ser tipificados en la legislación interna de los Estados Parte en el Convenio ${ }^{5}$ y castigados con penas adecuadas, lo que no implica, necesariamente, que las penas sean superiores a las previstas en el Derecho interno de cada uno de los Estados Parte para los mismos actos, pero contra personas que no son «internacionalmente protegidas». Otro de los aspectos clave de la Convención reside en la cooperación entre los Estados Partes para prevenir la perpetración de los delitos y para intercambiar información y asegurar el castigo de los culpables.

A la vista de este resumen básico, parece obvio que la finalidad última de la Convención es encauzar la cooperación legislativa, judicial y policial entre los Estados Partes con el fin de prevenir la comisión de los actos previstos en ella y de castigar a sus culpables. Ahora bien, pese a ser éste

${ }^{3}$ Cfr. G. Guilaume, Las grandes crisis internacionales y el Derecho, Ariel, Barcelona, 1995, p. 194.

${ }^{4} \mathrm{El}$ art. 1 define quiénes son las «personas internacionalmente protegidas» y los presuntos autores del ilícito. El art. 2 se centra en la determinación de los tipos punibles. Los arts. 3 a 12, con matices, articulan la regla aut dedere aut iudicare y un sistema de intercambio de información entre los Estados Partes. El art. 13 se centra en el sistema de solución de controversias, estableciendo, en su párrafo 1, un recurso obligatorio a instancia de parte, y una vez hayan fallado los intentos de negociación, a la jurisdicción obligatoria, lo que ha dado lugar a la mayor parte de las reservas formuladas a la Convención, en uso del párrafo 2 del propio art. 13, que prevé tal posibilidad. Los arts. 14 a 20 recogen las disposiciones finales.

5 En el Código Penal español los delitos contra personas internacionalmente protegidas se contienen en el Libro II, Título XXIV, «Delitos contra la comunidad internacional», Capítulo I, «Delitos contra el derecho de gentes» (arts. 605-606). Existe múltiple bibliografía sobre la tipificación de estos delitos en el Derecho interno español. Entre otros muchos citaré a M. PÉrez González y M. Abad Castelos, «Los delitos contra la comunidad internacional en el Código Penal español», Anuario da Facultade de Dereito da Universidade da Coruña, núm. 3, 1999, pp. 433-468. 
su objetivo, es un complemento necesario de los convenios codificadores de Derecho diplomático y consular, constituyendo, como señaló la Sexta Comisión de la Asamblea General de las Naciones Unidas, un medio para dar efecto práctico a los conceptos de inviolabilidad y protección especial de dichos tratados ${ }^{6}$, recogidos básicamente en los arts. 22, 29 y 30 del Convenio de Viena sobre relaciones diplomáticas de 1961 y en los arts. 31 y 41 del Convenio de Viena sobre relaciones consulares de 1963. Por su interés práctico, haré una breve referencia al contenido básico de estas disposiciones, haciéndolas extensivas a lo que, en la Convención de Nueva York de 1973 objeto de este comentario, se denominan, de forma omnicomprensiva, «personas internacionalmente protegidas»:

- Inviolabilidad de los locales (arts. 22 de la Convención de Viena de 1961 y 31 de la Convención de Viena de 1963): bajo esta regla general, el Estado receptor tiene el deber de abstenerse de ejercer derechos soberanos respecto de las dependencias diplomáticas y consulares, las personas protegidas y la propiedad de éstas. Es ésta, por tanto, una obligación de índole negativa, pero también hay una obligación de carácter positivo a cargo del Estado receptor: dicho Estado debe proteger de cualquier atentado físico o interferencia que pueda menoscabar la dignidad de las dependencias o las personas internacionalmente protegidas ${ }^{7}$.

- Inviolabilidad de las «personas internacionalmente protegidas» (arts. 29 del Convenio de Viena de 1961 y 41 del Convenio de Viena de 1963): la inviolabilidad de las «personas internacionalmente protegidas» reviste dos clases de obligaciones a cargo del Estado receptor: una, nega-

${ }^{6}$ Cfr. E. Vilariño Pintos, Curso de Derecho diplomático y consular, 3. ${ }^{a}$ ed., Tecnos, Madrid, 2007, p. 128. Este autor señala que la Resolución 3166 (XXVIII) de la Asamblea General de las Naciones Unidas, que adopta el Convenio, no hace expresa referencia a la codificación y desarrollo progresivo del Derecho diplomático, sino, en términos generales, del Derecho internacional, y que en el Preámbulo del propio Convenio no se mencionan los convenios codificadores del Derecho diplomático y consular ya adoptados en ese momento (Convenio de Viena de 1961 y de 1963, respectivamente), ni tampoco en el Convenio de 1975 se le menciona como parte integrante del Derecho diplomático y consular.

7 Vid. E. DeNZA, op. cit., pp. 112-156.

La realización práctica de esta inviolabilidad, en relación con la Convención de Nueva York de 1973, podría hacer que esta última quedase inaplicada en virtud del denominado «derecho de asilo diplomático», es decir, en la medida en que una persona presuntamente culpable de uno de los delitos recogidos en el art. 2 de la Convención de 1973 buscase asilo en la misión diplomática de un Estado amigo que pudiese llegar a reputar su delito como «político». En pura teoría, las cosas podrían ser como se acaba de describir; en la práctica, en cambio, el asilo diplomático exige que la persona beneficiaria del mismo sea una persona acusada de delitos políticos, ámbito en el que no entrarían, sin lugar a dudas, los tipos delictivos del art. 2 de la Convención de Nueva York de 1973. 
tiva, abstenerse de ejercer medidas de fuerza contra dichas personas; otra, positiva, protegerlo de cualquier ataque contra su persona, su libertad o su dignidad. Desde la adopción del Convenio de Viena de 1961, la obligación positiva de proteger quedó en entredicho precisamente porque los agentes diplomáticos, por su significación pública y por ostentar tales privilegios, se convirtieron en blanco predilecto de los grupos terroristas, de modo que se planteó el alcance práctico del art. 29 del Convenio de Viena sobre relaciones diplomáticas de 1961: para proteger la inviolabilidad del agente diplomático debe el Estado receptor tomar todas las medidas adecuadas, pero ¿comprenden éstas el pago de un rescate o la violación del propio Derecho interno entablando una negociación con los terroristas? La respuesta a esta pregunta ha dependido de los supuestos de la práctica internacional, de forma que, en ocasiones, el Estado receptor ha cedido a las peticiones de los terroristas con tal de salvaguardar al agente diplomático, mientras que en otras ocasiones se ha negado a hacerlo, a veces con resultado fatal para la persona del agente diplomático ${ }^{8}$.

- Inmunidad de jurisdicción (penal, absoluta, civil y administrativa, relativas) de las personas internacionalmente protegidas (arts. 30 de la Convención de Viena de 1961 y 41.3 de la Convención de Viena de 1963), lo que podría considerarse una extensión de su inviolabilidad personal. Extendiendo la disposición de estos artículos a otras personas internacionalmente protegidas, como los jefes de Estado y de gobierno y los ministros de Asuntos Exteriores, es evidente que la inmunidad penal absoluta, a día de hoy, no podría reconocerse a personas internacionalmente protegidas que hayan incurrido en un crimen de lesa humanidad, y ello pese al punto de vista distinto y extremadamente conservador de la jurisprudencia internacional representada por la Corte Internacional de Justicia? .

${ }^{8}$ En 1970 el embajador de la República Federal de Alemania en Guatemala, el conde Von Spreti, fue secuestrado y los secuestradores, a cambio de su rescate, pidieron la liberación de prisioneros. Guatemala entendió que el art. 29 del Convenio de Viena de 1961 no exigía violar su Derecho interno o poner en peligro su propia seguridad nacional, de modo que no accedió a las peticiones de los secuestradores. El embajador fue asesinado, la República Federal de Alemania protestó ante el gobierno de Guatemala por considerar que había incumplido sus obligaciones dimanantes del art. 29 del Convenio de Viena y, prácticamente, rompió relaciones diplomáticas con Guatemala. Cfr. E. DENZA, op. cit., pp. 212-213.

9 Vid., entre la amplia bibliografía sobre el tema, R. CARNERERO CASTILLA, La inmunidad de jurisdicción penal de los jefes de Estado extranjeros, Iustel, Madrid, 2007, y del mismo autor, «Un paso atrás en la lucha contra la impunidad. La Sentencia de la Corte Internacional de Justicia de 14 de febrero de 2002 en el asunto relativo a la orden de arresto de 11 de abril de 2000 (República Democrática del Congo c. Bélgica)», en J. Quel López y A. G. LóPez MARTín (coords.), El poder de los jueces y el estado actual del Derecho internacional, UPV, Bilbao, 2010. 


\section{HISTORIA LEGISLATIVA DE LA CONVENCIÓN SOBRE PREVENCIÓN Y CASTIGO DE DELITOS CONTRA PERSONAS INTERNACIONALMENTE PROTEGIDAS, INCLUIDOS LOS AGENTES DIPLOMÁTICOS (NUEVA YORK, 1973)}

\section{Antecedentes}

La Convención sobre prevención y castigo de delitos contra personas internacionalmente protegidas, incluidos los agentes diplomáticos, tiene en cuenta los precedentes de otros tratados internacionales anteriores de carácter sectorial, como la Convención para la supresión del apoderamiento ilícito de aeronaves (La Haya, 16 de diciembre de 1970) y la Convención para la represión de actos ilícitos contra la seguridad de la aviación civil (Montreal, 23 de septiembre de 1971), aunque en buena medida se aparta de aquéllas. Asimismo, para la comprensión de este tratado es necesario tener presentes otros textos jurídicos básicos, como ya he señalado, que codifican el Derecho diplomático y consular, como las Convenciones de Viena sobre relaciones diplomáticas y sobre relaciones consulares de 1961 y 1963, respectivamente, o la Convención de Nueva York sobre misiones especiales de 1969, pues dichos instrumentos adquieren en buena parte sentido y efectividad práctica gracias a la Convención de Nueva York de 1973. Es preciso, por lo demás, tener en cuenta que, en el proceso de elaboración de este tratado, los órganos implicados en su redacción, particularmente la Comisión de Derecho Internacional (en adelante, CDI) y la Sexta Comisión de la Asamblea General de las Naciones Unidas, tuvieron presentes otros textos jurídicos conexos con el tema, como la Convención para prevenir y sancionar los actos de terrorismo configurados en delitos contra las personas y la extorsión conexa cuando éstos tengan trascendencia internacional (Washington, 2 de febrero de 1971, conocida como Convención de la Organización de Estados Americanos, OEA); un proyecto de Convención relativo a los crímenes contra diplomáticos, elaborado por un grupo de Estados reunidos en Roma en febrero de $1971^{10}$ («el proyecto de Roma»); un proyecto de Convención relativo a los crímenes cometidos contra diplomáticos, que fue remitido al 27..$^{\circ}$ periodo de sesiones de la Asamblea General de las Naciones Unidas

${ }^{10}$ UN Doc. A/CN.4/253/Add.2 (1972). 
por la delegación de Uruguay ${ }^{11}$ («el documento de trabajo de Uruguay»), y un proyecto de artículos relativo a los crímenes cometidos contra personas que requieren de especial protección según el Derecho internacional, contenido en un documento de trabajo ${ }^{12}$ preparado por el señor Kearney, presidente en aquel momento de la CDI ${ }^{13}$.

\section{Del proyecto de artículos de la CDI a la adopción de la Convención por la Asamblea General}

En mayo de 1970, el representante de los Países Bajos ante las Naciones Unidas dirigió una carta al presidente del Consejo de Seguridad de la organización relativa a la necesidad de tomar medidas para asegurar la protección y la inviolabilidad de los agentes diplomáticos, teniendo en cuenta que se habían convertido en el blanco predilecto de múltiples grupos violentos.

La Asamblea General, en la Resolución 2.780 (XXVI), de 3 de diciembre de 1971, solicitó a la Comisión de Derecho Internacional el estudio de esta materia y la preparación de un proyecto de artículos que dicho órgano debería remitir a la Asamblea General para su consideración. Asimismo, en dicha resolución requirió al Secretario General para que invitara a los Estados miembros a trasladar sus comentarios sobre el proyecto a la CDI ${ }^{14}$.

11 UN Doc. A/C.6/L.822 (1971).

12 UN Doc. A/CN.4/L.182 (1972).

13 Cfr. M. C. WoOd, «The Convention on the Prevention and Punishment of Crimes Against Internationally Protected Persons, Including Diplomatic Agents», International and Comparative Law Quarterly, vol. 23, 1974, pp. 792-793.

14 En su 24. ${ }^{\circ}$ periodo de sesiones, en 1972, la Comisión creó un grupo de trabajo con el fin de que éste elaborara un proyecto de artículos para ser estudiado por la CDI. Este procedimiento fue, por tanto, diferente al seguido habitualmente por la Comisión, que suele nombrar un relator especial para que realice ese trabajo, y ello fue debido a que en la revisión y estudio general de la materia, la mayoría de los miembros de la CDI estimaron que se necesitaba un procedimiento más expeditivo de trabajo, dada la urgencia y la importancia del tema a tratar, para remitir un proyecto de artículos a la AGNU en su 27. ${ }^{\circ}$ periodo de sesiones.

El grupo de trabajo remitió un primer informe a la CDI que contenía doce artículos. Tras su consideración por la CDI, el grupo de trabajo revisó su labor y sometió a la consideración de la CDI dos nuevos informes. Sobre la base de los mismos, la CDI aprobó el proyecto de doce artículos y lo remitió a la Asamblea General y a los gobiernos para que presentaran sus comentarios. El proyecto de artículos, en líneas generales, se centró en tres aspectos fundamentales:

a) El ámbito de aplicación del proyecto rationae personae y rationae materiae (arts. 1 y 2). El art. 2, asimismo, versaba sobre la aplicación del principio de jurisdicción universal para la represión de los culpables de los actos en él enumerados. 
En su Resolución 2.926 (XXVII), de 28 de noviembre de 1972, la Asamblea General decidió considerar el proyecto de convención en su 28..$^{\circ}$ periodo de sesiones, con el fin de elaborar un tratado internacional sobre la materia, al tiempo que invitaba a los gobiernos, a las organizaciones intergubernamentales y a los organismos especializados a presentar sus observaciones sobre el texto. El 14 de diciembre de 1973, la Asamblea General adoptó la Convención sobre prevención y castigo de delitos contra personas internacionalmente protegidas, incluidos los agentes diplomáticos, formada por un Preámbulo y 20 artículos, anexa a la Resolución 3.166 (XXVIII), de 14 de diciembre de 1973. La Convención quedó abierta a la firma para todos los Estados el 31 de diciembre de 1974. Se fijó, como modo de manifestación del consentimiento, la ratificación. Entró en vigor el 20 de febrero de $1977^{15}$.

\section{EL AMBITO DE APLICACIÓN MATERIAL DE LA CONVENCIÓN DE NUEVA YORK DE 1973}

La cuestión relativa a la aplicación material de la Convención —rationae personae, rationae materiae y rationae temporis - es abordada, respectivamente, en los arts. 1, 2 y 17, relativo, este último, a la entrada en vigor, que parte, por tanto, de la presunción general de irretroactividad de la norma.

\section{1. Ámbito de aplicación rationae personae}

El art. 1.1 recoge el ámbito de aplicación (activa) rationae personae de la Convención, entendiendo por «personas internacionalmente protegidas»,

b) Los arts. 3 y 4 trataban de promover la cooperación y la comunicación entre los Estados Partes a fin de prevenir los actos de terrorismo y a fin de asegurar el ejercicio de la jurisdicción — lo que no implica necesariamente el castigo- contra los presuntos culpables.

c) Los arts. 5, 6 y 7 trataban de dar efectividad al principio de jurisdicción universal enunciado en el art. 2 implementando, a su vez, la regla general aut dedere aut iudicare. Vid. «Draft articles on the prevention and punishment of crimes against diplomatic agents and other internationally protected persons with commentaries», Yearbook of the International Law Commission, vol. II, 1972, pp. 312-350, A/CN.4/SER.A/1972/Add.1.

${ }^{15}$ Cfr. Extracts from The Work of the International Law Comision, vol. 1, 7. ${ }^{\mathrm{a}}$ ed., disponible en http://www.un.org/law/ilc/. 
en sus apartados $a$ ) y b), un conjunto amplio de personas que gozan de protección internacional en ejercicio de sus funciones en un Estado extranjero en tanto que representantes de un Estado o de una organización internacional o funcionarios de los mismos, extendiendo la protección a los miembros de sus familias que acompañen a los jefes de Estado, de gobierno o ministros de Asuntos Exteriores [apartado a) in fine] y a los miembros de las familias de los funcionarios y de los representantes de Estados y organizaciones internacionales que formen parte de su casa [apartado $b$ ) in fine]. En sus reservas, algunos Estados, como Irak (párrafo 2 de su reserva de 28 de febrero de 1978), entienden, con una visión amplia de la expresión «personas internacionalmente protegidas», «a los representantes de los movimientos de liberación nacional reconocidos por la Liga de Estados Árabes o la Organización de la Unidad Africana» ${ }^{16}$. Francia, en una declaración más cabal, señala que la Convención objeto de comentario se aplicará sin perjuicio de la Convención adoptada en Nueva York el 9 de diciembre de 1994 sobre la seguridad del personal de las Naciones Unidas y del personal asociado.

Por su parte, el art. 1.2 delimita, rationae personae, el ámbito de aplicación (pasiva) de la Convención, entendiendo por «presunto culpable» aquel contra el que existan suficientes elementos de prueba como para considerar que ha cometido alguno de los actos tipificados en el Convenio. A este respecto es reseñable la precisión que, en sus reservas a la Convención, hacen Colombia y Malasia, entendiendo por «presunto autor de la infracción» al «acusado».

\section{Un aspecto problemático: la tipificación de los delitos punibles}

Es el art. 2 el que se ocupa de la tipificación de los actos punibles, habiendo dado esta cuestión lugar a controversia en el proceso de elaboración de la Convención. Debe tenerse en cuenta que el texto de la Convención es en este punto sustancialmente distinto del recogido, en su proyecto de artículos, por la CDI. En efecto, a diferencia de la relación pormenorizada de crímenes que recoge el art. 2 de la Convención, más una fórmula

${ }_{16} \mathrm{Al}$ respecto manifestó su objeción, declarando que tal reserva no tendría efecto jurídico alguno para la República Federal de Alemania (30 de noviembre de 1979). En el mismo sentido se manifestaron, planteando sus objeciones a dicha reserva, Italia (30 de agosto de 1985) y Reino Unido de Gran Bretaña e Irlanda del Norte (2 de mayo de 1979). 
amplia y omnicomprensiva que se recoge en el art. 2.1.b $)^{17}$, el proyecto de la CDI señalaba, de forma más genérica, lo siguiente:

«La comisión intencionada, sea cual fuere el motivo, de:

a) Un atentado violento contra la integridad física o la libertad de una persona internacionalmente protegida» ${ }^{18}$.

El hecho de que en el texto de la Convención no aparezcan las palabras «sea cual sea el motivo»y, asimismo, que se expliciten en el apartado a) del art. 2.1 los posibles delitos, no deja de tener importancia por los motivos siguientes:

1. Por lo que se refiere a la segunda de las cuestiones apuntadas -el hecho de que se haga mención expresa de los tipos delictivos-, puede plantear problemas en relación con supuestos de extradición, puesto que los Estados requeridos pueden exigir que el Estado requirente defina dichos delitos en los mismos términos que aquél. No obstante, dicho problema dejaría de serlo teniendo en cuenta la naturaleza básica de los tipos enumerados más la fórmula aglutinadora final — «u otro atentado...»—, por otra parte, uno de los principios informativos de la extradición es que la petición (de extradición) debe apoyarse en la identidad tipológica normativa, no en el nomen iuris ${ }^{19}$. En este sentido, es significativa la reserva a dos disposiciones de la Convención hecha por Malasia, que señala:

«2. El gobierno de Malasia entiende que por la expresión " $\mathrm{u}$ otro ataque”, contenida en el párrafo 1.a) del art. 2 de la Convención, se entenderán actos constitutivos de infracciones según el Derecho interno.

${ }^{17}$ Que señala:

«1. Serán calificados por cada Estado Parte como delitos en su legislación interna, cuando se realicen intencionalmente:

a) La comisión de un homicidio, secuestro u otro atentado contra la integridad física o la libertad de una persona internacionalmente protegida.

b) La comisión de un atentado violento contra los locales oficiales, la residencia particular o los medios de transporte de una persona internacionalmente protegida que pueda poner en peligro su integridad física o su libertad.

c) La amenaza de cometer tal atentado.

d) La tentativa de cometer tal atentado.

e) La complicidad en tal atentado.

$[\ldots] \gg$

${ }^{18}$ Cursiva añadida, traducción de la autora.

19 Cfr. J. Valle-Riestra González-Olaechea, La extradición y los delitos políticos, Navarra, The Global Law Collection, Garrigues Cátedra Universidad de Navarra-Thomson Aranzadi, 2006, p. 24. 
3. El gobierno de Malasia entiende que el art. 7 de la Convención comprende el derecho de las autoridades competentes de decidir no iniciar actuaciones judiciales en los casos concretos en que se apliquen al presunto infractor las leyes en materia de seguridad nacional y detención preventiva».

Pues bien, este último apartado de la reserva de Malasia ha dado lugar a no pocas objeciones, pues al subordinar Malasia la interpretación y la aplicación del art. 7 del Convenio a su legislación nacional, «introduce una reserva general e imprecisa que hace imposible determinar claramente de qué manera se propone modificar las obligaciones derivadas del Convenio» ${ }^{20}$.

2. Más problemático es, sin duda, el hecho de que de la redacción final del tratado desapareciera la referencia a la expresión «cualquiera que sean los motivos» que sí aparece en el proyecto de la CDI. Es, sin duda, la prueba de que nos encontramos ante un instrumento jurídico adoptado en los años setenta del pasado siglo en los que, como ya he señalado, si bien no faltaron ejemplos de actos delictivos contra personas internacionalmente protegidas, los atentados terroristas no fueron de la magnitud de los conocidos en los primeros años del siglo XXI, ni crearon semejante alarma social; por otro lado, una parte nada despreciable de los Estados del mundo habían acabado de acceder a la vida internacional como tales sujetos después de cruentas luchas por su independencia contra la potencia colonial, luchas en las que se incluyeron actos que hoy se calificarían de «terrorismo», independientemente de sus motivaciones subyacentes. Pues bien, la desaparición de la expresión «cualquiera que sean los motivos» que se encuentran detrás de los actos tipificados podría hacer de la Convención papel mojado, en la medida en que algunos Estados podrían considerar los atentados como «delitos políticos o justificados en base a razones políticas». Téngase en cuenta que aún en la actualidad no contamos con una definición unánimemente compartida, a escala universal, de lo que es el terrorismo, precisamente por los múltiples intereses políticos que su determinación pone en juego ${ }^{21}$. En todo caso, y a la vista de los

${ }^{20}$ Cfr. Objeción de 3 de noviembre de 2004 de la República Federal de Alemania. En el mismo sentido, la objeción de Países Bajos (6 de diciembre de 1988).

${ }^{21}$ «Los trabajos desarrollados a escala universal, en el seno de la Asamblea General de las Naciones Unidas, con el fin de concluir un convenio general para la represión del terrorismo, se encuentran, precisamente a causa de la polémica definición del fenómeno, en un punto muerto. A este respecto, las cuestiones que más controversia han causado al intentar definir el término han sido las siguientes:

- el terrorismo de Estado o el llevado a cabo por las fuerzas militares y de seguridad 
desarrollos muy posteriores a la Convención, que casi tiene cuarenta años, es más que dudoso - aunque no imposible, como lo prueba el estado de las recientes relaciones entre España y Venezuela $-{ }^{22}$ que a día de hoy un Estado pueda llegar a amparar como delito político un atentado de estas características contra personas internacionalmente protegidas, al menos por la cuenta que le puede traer ${ }^{23}$.

del propio Estado o incluso por particulares que, de forma encubierta, actúan por cuenta del aparato del Estado;

- los actos desarrollados, en su lucha de liberación, por los movimientos de liberación nacional;

- la distinción del terrorismo de otras actividades ilícitas, en la medida en que los medios utilizados por uno y otras pueden ser los mismos o, incluso, en la medida en que suele haber conexiones entre ambos tipos de actividades;

- la distinción del terrorismo de los grupos guerrilleros: estos últimos aspiran a obtener el gobierno de un país, actúan, por tanto, en el marco de un conflicto armado y, en consecuencia, se les debe aplicar el derecho bélico humanitario; sin embargo, los grupos terroristas, en principio, perseguirían presionar al gobierno de uno o varios países con un objetivo político.

La definición ofrecida por el Consejo de Seguridad en su Resolución 1566 (2004) parece la más convincente de las adoptadas hasta el momento en el seno de la organización universal, si bien es preciso advertir al lector de que adolece de importantes defectos:

"... actos criminales, incluyendo los cometidos contra civiles, cometidos con la intención de causar muerte o daños graves, o la toma de rehenes, con el propósito de provocar un estado de terror en el público en general o en un grupo de personas en particular, con el fin de intimidar a la población o de obligar al gobierno o a una organización internacional a hacer o a abstenerse de hacer cualquier acto y cualesquiera otros actos que puedan constituir una ofensa en el marco de cualquier convención internacional y protocolos relativos al terrorismo, son bajo ninguna circunstancia justificables en orden a motivos políticos, filosóficos, ideológicos, raciales, étnicos, religiosos o de cualquier otra naturaleza"».

Cfr. E. CONDE PÉREZ, «Terrorismo e imputación al Estado: algunos supuestos de la práctica internacional», en M. PÉREZ GonZÁLEZ (ed.), Lucha contra el terrorismo. Derecho penal internacional y Derecho internacional bumanitario, Tirant lo Blanch, Valencia, en prensa.

${ }^{22}$ La Audiencia Nacional española investiga las conexiones entre ETA y la guerrilla colombiana, presuntamente entrenada por ETA en suelo venezolano y con la presunta connivencia de funcionarios de la Administración de Hugo Chávez. Vid. «Así entrenó ETA en Venezuela», El País, 7 de marzo de 2010.

${ }^{23}$ La doctrina Bush posterior al 11-S equipara absolutamente al Estado terrorista con el que da amparo o cobija el terrorismo, suponiendo, en consecuencia, un importante cambio respecto de los requisitos que tradicionalmente, y recogidos por la CDI en su proyecto de artículos sobre la responsabilidad del Estado por hechos internacionalmente ilícitos (aprobado por la CDI en su 53. ${ }^{\circ}$ periodo de sesiones, agosto de 2001), se venían exigiendo para atribuir un acto terrorista al Estado. En apoyo de esta tesis se invocan, por parte de la doctrina, las resoluciones del CSNU en el marco del Capítulo VII respecto de Libia, Sudán y el régimen talibán en Afganistán. Este cambio es, asimismo, el que ha hecho surgir dos grandes corrientes de pensamiento en torno al uso de la legítima defensa (art. 51 de la Carta de las Naciones Unidas):

«1. Según la escuela de pensamiento que podríamos denominar "clásica", la legítima defensa es un uso de la fuerza de Estado a Estado, y sólo cuando se pudiera atribuir un acto 
En este contexto de la delimitación de los tipos delictivos habría que entender, asimismo, el art. 12 -que salvaguarda los tratados sobre asilo vigentes en la fecha de adopción de la Convención-, tampoco incluido en el proyecto de artículos original de la CDI, así como la no desdeñable referencia que en el párrafo 4 de la Resolución 3.166 (XXXVIII) (1974), a la que se anexa la Convención, se hace respecto del derecho de libre determinación de los pueblos:

- Art. 12. Ya en el seno de la CDI algunos miembros señalaron la necesidad de que se tuvieran en cuenta los tratados de asilo con respecto a los delitos políticos, si bien la idea general en tal órgano fue la de que los actos tipificados en el Convenio en ningún caso cubrían los delitos políticos, por lo que la referencia a dicha cuestión en el proyecto de artículos de la CDI no aparece. Teniendo en cuenta el precedente de la Convención de la OEA (1971), que recoge la referencia a dichos tratados, Bolivia ${ }^{24}$ propuso un nuevo texto que, ligeramente cambiado por el comité de redacción, pasaría a ser el actual art. 12. El temor que surgió entonces fue el de que la libre determinación, dejando en manos de cada Estado la cuestión de qué se entiende por «delito político», podría echar por tierra la obligación aut dedere aut indicare, que es la razón última de ser del tratado. Para limitar los posibles efectos perniciosos se contiene, así, en el art. 12, un sistema muy limitado de aplicación de los tratados de asilo que consiste en lo siguiente:

terrorista a un Estado sería válido su uso [es la opinión de la Corte Internacional de Justicia en el dictamen sobre la legalidad de la construcción de un muro en territorio palestino ocupado, CIJ Recueil (2004), en http://www.icj-cij.org/docket/files/131/1671.pdf].

2. Según la escuela de pensamiento que podríamos denominar "emergente", el uso de la fuerza sería legítimo aun cuando no fuera posible atribuir directamente el ataque terrorista al Estado en cuestión. Desde este punto de vista, la incapacidad del Estado para prevenir los ataques terroristas o el apoyo a ese terrorismo, sin que se le pudiera atribuir directamente dicha actividad, bastaría para lanzar una respuesta armada contra objetivos terroristas en ese Estado, simplemente porque el Estado huésped ha incumplido su obligación de prevenir. Los precursores de esta doctrina sugieren así que las instalaciones del Estado huésped pueden ser objetivos incidentales de la acción de defensa legítima dirigida contra el grupo terrorista en un claro reto al necesario requisito de la "proporcionalidad" tradicionalmente vigente para que la defensa pueda ser catalogada como "legítima".

La diferencia básica entre una escuela de pensamiento y otra es que, mientras la primera exige la atribución directa de responsabilidad al Estado para que el ataque sea legítimo, para la segunda ello sólo afecta al ámbito de los objetivos permitidos, lo que explica que este tipo de operaciones hayan sido discutidas desde el punto de vista de su proporcionalidad». Cfr. E. Conde PéREZ, «Terrorismo e imputación al Estado...», op. cit.

${ }^{24}$ UN Doc. A/C.6/L.943 (1973). 
1. El art. 12 sólo se refiere a los tratados de asilo en vigor en el momento de adopción de la Convención (14 de diciembre de 1973).

2. La segunda frase del artículo limita, aún más, su ámbito de aplicación, pues los tratados de asilo sólo serán aplicables entre Estados Partes en ellos ${ }^{25}$.

3. El art. 12 vendría a ser un acuerdo, entre algunos de los Estados Partes en el Convenio, para modificar el alcance del mismo, que estaría regido por el art. 41 del Convenio de Viena sobre el derecho de los tratados (1969), que en su apartado $b$ ) especifica que será posible dicho acuerdo siempre y cuando

«i) no afecte al disfrute de los derechos que a las demás partes correspondan en virtud del tratado ni al cumplimiento de sus obligaciones, e ii) no se refiera a ninguna disposición cuya modificación sea incompatible con la consecución efectiva del objeto y fin del tratado en su conjunto» ${ }^{26}$.

${ }^{25}$ En relación con esta segunda frase, es interesante la reserva formulada por el gobierno de los Países Bajos (6 de diciembre de 1988) en el sentido de que dicha frase «no afectaría en modo alguno la aplicabilidad del art. 33 de la Convención de 28 de julio de 1951 sobre el Estatuto de los Refugiados». El art. 33 de la mencionada Convención señala:

«1. Ningún Estado contratante podrá, por expulsión o devolución, poner en modo alguno a un refugiado en las fronteras de territorios donde su vida o su libertad peligre por causas de su raza, religión, nacionalidad, pertenencia a determinado grupo social o de sus opiniones políticas.

2. Sin embargo, no podrá invocar los beneficios de la presente disposición el refugiado que sea considerado, por razones fundadas, como un peligro para la seguridad del país donde se encuentra, o que, habiendo sido objeto de una condena definitiva por un delito particularmente grave, constituya una amenaza para la comunidad de tal país».

${ }^{26}$ Vid. A. B. GREEN, op. cit., pp. 708-710, y M. C. WoOD, op. cit., pp. 813-815. En este mismo sentido, Wood recoge las palabras del representante de Estados Unidos en el Pleno de la Asamblea General en explicación del voto de Estados Unidos en el acto de adopción de la Convención, quien señaló:

«El artículo señala que esta Convención no afectará a la aplicación de los tratados de asilo en vigor entre los Estados Partes en dichos tratados inter se. Esto significa que, si el presunto culpable se encuentra en el territorio de un Estado Parte en uno de tales tratados y si el Estado en cuyo territorio se ha cometido el crimen es también parte en el tratado, si la persona internacionalmente protegida atacada ejercía sus funciones en representación de un Estado no parte en el tratado de asilo o si el presunto culpable es nacional de un Estado no parte en tal tratado, el Estado donde se encuentra el presunto culpable no puede invocar dicho tratado frente a un Estado que no es parte en él. Eso significa que el Estado no parte en el tratado de asilo puede requerir al Estado en cuyo territorio se encuentra el presunto culpable para que cumpla sus obligaciones de conformidad con el art. 7 y también, si así lo desea, puede requerir su extradición de conformidad con el art. 8» (traducción de la autora). Apud M. C. Wood, op. cit., pp. 814-815.

Más en términos generales, sobre terrorismo y derecho de asilo, en E. CONDE PéREZ, «TEDH, Sentencia de 28-02-2008, Saadi c. Italia, 3701/06. Art. 3 CEDH, prohibición de 
- El derecho de libre determinación de los pueblos. Ya he señalado que la Convención objeto de este estudio aparece anexa a la Resolución 3.166 (XXVIII) de la Asamblea General, de 14 de diciembre de 1973, hecho que, en sí, no altera la naturaleza de la norma, pues dicho acto sigue constituyendo la adopción del texto del tratado. Es significativo, no obstante, que el párrafo 4 de tal Resolución haga una referencia al principio de libre determinación de los pueblos en su relación con el ámbito de aplicación material de la Convención, en concreto señala:

$\ll[\ldots]$

4. Reconoce asimismo que las disposiciones de la Convención contenidas en el anexo de esta Resolución en ningún caso podrán comprometer el ejercicio del legítimo derecho de libre determinación e independencia con arreglo a los propósitos y principios de la Carta de las Naciones Unidas y a la Declaración sobre los principios de Derecho internacional referentes a las relaciones de amistad y a la cooperación entre los Estados de conformidad con la Carta de las Naciones Unidas por los pueblos que luchan contra el colonialismo, la dominación extranjera, la discriminación racial y el apartheid».

Para mejor comprender el contenido de este párrafo es necesario situarse en el contexto histórico del momento en el que la adopción de la Convención tiene lugar: hoy día el ejercicio del derecho de libre determinación no podría en ningún caso servir para calificar de «políticos» los crímenes contemplados en la Convención y eludir, de ese modo, su persecución o enjuiciamiento ${ }^{27}$. En la Asamblea General de las Naciones Unidas, las posturas al hilo de la apreciación jurídica y del alcance de este párrafo se dividieron entre los que consideraron que los crímenes contemplados por la Convención no podrían en ningún caso justificarse bajo el amparo del principio de libre determina-

torturas y penas o tratos inhumanos o degradantes. Terrorismo $v$. Tortura», Revista de Derecho Comunitario Europeo, vol. 32, 2009, pp. 275-290.

${ }^{27} \mathrm{El}$ «delito político» es difícil de circunscribir en términos generales, sobre todo en razón de su materia o su objetivo, lo que lleva al test del medio empleado: «Si ese medio es vandálico, de peligro común, contra el derecho de gentes, no puede recibir la dignidad de delito político. [...] El terrorista, subjetivamente, puede creer que lucha por el socialismo. Puede incluso atacar objetivos estatales o personas vinculadas al gobierno, pero sus métodos vesánicos, en que proclama "todos son culpables" y, por eso, se siente con licencia para atacar objetivos civiles inocentes, lo proscribe del Derecho». Cfr. J. VALLE-RiestRA GONZÁLeZ-OlaECHEA, op. cit., pp. 71-72, y E. VIlaRiÑo PINTOS, «Terrorismo y la cooperación penal internacional en las relaciones bilaterales entre España y los Estados latinoamericanos», en M. PÉREz González (ed.), Lucha contra el terrorismo. Derecho penal internacional y Derecho internacional bumanitario, Tirant lo Blanch, Valencia, en prensa. 
ción $^{28}$, o los que invocaron las excepciones muy limitadas al principio de prohibición del uso o la amenaza de la fuerza en la Carta de las Naciones Unidas, y los que, en cambio, hicieron prevalecer el principio de libre determinación de los pueblos frente al contenido de la Convención ${ }^{29}$. Llama en todo caso la atención que dicha referencia no se contenga en el texto de la Convención, lo que ha sido interpretado, a su vez, de formas diversas: así, para algunos - los que intentan limitar su alcance en aras de la Convención-, el párrafo 4 es una declaración general sobre el derecho de libre determinación de los pueblos; en cambio, para los más rupturistas, el hecho de que la Convención vaya anexa a la Resolución en la que se contiene tal párrafo 4 obliga a aplicar a dicha resolución el art. 31 del Convenio de Viena sobre el derecho de los tratados (1969), relativo a las reglas de interpretación de éstos, que en su párrafo 2 dispone:

«2. Para los efectos de la interpretación de un tratado, el contexto comprenderá, además del texto, incluidos su preámbulo y anexos:

a) todo acuerdo que se refiera al tratado y haya sido concertado entre todas las partes con motivo de la celebración del tratado».

Personalmente, sea cual sea el alcance práctico que haya podido llegar a tener el párrafo 4 de la Resolución, entiendo que esta última interpretación es la más acertada, esto es, que la resolución y la Convención han de interpretarse como un todo unitario ${ }^{30}$. Así, en relación con este párrafo de la Resolución 3.166 (XXVIII), Burundi manifestó la siguiente reserva a la Convención:

«Respecto de los casos en que los pretendidos delincuentes pertenezcan a un movimiento de liberación nacional reconocido por Burundi o por una organización internacional de que Burundi sea miembro, y sus acciones sean parte de su lucha por la liberación, el gobierno de la República de Burundi se reserva el derecho de no aplicarles las disposiciones del art. 2, párrafo 2, y del art. 6, párrafo primero».

Como es lógico, dicha reserva ha suscitado no pocas objeciones, como la de la República Federal de Alemania formulada el 25 de marzo de 1981, que la considera incompatible con el objeto y fin del tratado, la de Israel

${ }^{28}$ Como el representante del Reino Unido, UN Doc. A/P.2202 (1973), p. 112.

29 Argelia, Irak y Cuba, UN Doc. A/P.2202 (1973), pp. 26, 99 y 142.

${ }^{30}$ En este sentido se manifiesta Irak en el párrafo 1 de su reserva a la Convención. 
(28 de junio de 1982), Italia (30 de agosto de 1985) y Reino Unido de Gran Bretaña e Irlanda del Norte (15 de enero de 1982), que no consideran válida dicha reserva y, por tanto, no admiten como parte en el Convenio a Burundi hasta que no retire aquélla.

Para finalizar con el objeto material de la Convención y los tipos delictivos en ella contemplados, quiero señalar que un aspecto que creo criticable es, precisamente, el ámbito de aplicación material excesivamente amplio de la Convención: no cualquier atentado violento - especialmente los cometidos contra los locales oficiales - puede reputarse de terrorismo; para que ello sea así, estimo que el acto debe revestir cierta gravedad, pues lo que se conoce en los medios como «terrorismo de baja intensidad», a mi juicio no debería poner en marcha el mecanismo de represión que contempla la Convención ${ }^{31}$. A la vista del Informe del secretario general a la Asamblea General en su $63 .^{\circ}$ periodo de sesiones, en el que se recoge el «Examen de medidas eficaces para mejorar la protección y la seguridad de las misiones y los representantes diplomáticos y consulares» ${ }^{32}$, $y$, respecto de dicho tema, los informes de veintiún Estados sobre las infracciones graves de las normas más elementales sobre protección diplomática y consular (en sentido amplio), se puede adivinar que la mayor parte de las infracciones reportadas (hasta el año 2008) pertenecen a lo que he denominado «terrorismo de baja intensidad». En este sentido, las reservas a la Convención formuladas en este sentido por parte de Finlandia, la declaración de Francia y la de Tailandia (apartado 1) tienden a salvaguardar esta interpretación.

\section{LA REGLA AUT DEDERE AUT IUDICARE Y EL MÁS AMPLIO DEBER DE COOPERACIÓN PENAL INTERNACIONAL: SUPERACIÓN DEL SISTEMA PREVISTO EN LA CONVENCIÓN}

\section{Las reglas contenidas en los artículos 3 a 11 de la Convención}

La reglas contenidas en los arts. 3 a 11 de la Convención son supuestos de cooperación penal internacional que comprenden, en términos generales, tres ámbitos: extradición, asistencia judicial y traslado de personas condena-

${ }^{31}$ De hecho, en su funcionamiento «normal» los tratados de extradición exigen, para ponerse en marcha, una cierta gravedad del delito.

32 UN Doc. A/63/121 (27 de octubre de 2008). 
das ${ }^{33}$, pero también transmisión de procedimientos en materia penal y ejecución de sentencias penales, si bien, salvo la extradición, estas otras formas de evitar la impunidad no se llevan a la práctica de manera generalizada ${ }^{34}$.

A diferencia de lo que se establecía en el proyecto de Convenio de la CDI, con un sistema de jurisdicción universal, en el art. 3 de la Convención se recoge un sistema de jurisdicción primaria basada en los tradicionales conceptos de nacionalidad y personalidad jurídica pasiva: si el Estado Parte en cuyo territorio se encuentra el presunto culpable no es ni el Estado donde se ha cometido el delito ni el presunto culpable ni la víctima son nacionales de dicho Estado, tal Estado podrá ser requerido a 1) extraditar al presunto culpable a alguno de los Estados Partes con jurisdicción primaria, o 2) ejercer su jurisdicción sobre el presunto culpable. De esta forma, en el esquema final, los Estados con mayor interés o con interés primario en perseguir al culpable pueden solicitar su extradición al Estado donde aquél se encuentra, quien, en la lógica del Convenio, puede rechazar su extradición, pero, en tal caso, debe ejercer su jurisdicción sobre él ${ }^{35}$.

A su vez, el art. 7, en conjunción con el art. 3, se convierte en la razón de ser de la Convención, estableciendo, de forma clara, la obligación general aut dedere aut iudicare a cargo del Estado en cuyo territorio se encuentre el presunto culpable. Ahora bien, el alcance de la obligación contenida en el art. 7 debe evaluarse en su justa medida, como señaló la CDI al redactar en su proyecto de artículos una disposición idéntica (art. 6 del proyecto de artículos de la CDI):

«Tal y como está redactado el artículo, queda claro que, a su amparo, no se deriva una obligación de castigar o poner en marcha un proceso. La obligación del Estado Parte donde se encuentre el presunto culpable se verá satisfecha si dicho Estado remite el caso a sus autoridades competentes que, en la mayor parte de los casos, serán judiciales. Dependerá de esas autoridades la decisión acerca de si iniciar una causa judicial contra el pre-

33 Vid. E. Vilariño Pintos, «Terrorismo y la cooperación penal internacional...», op. cit.

${ }_{34}$ Cfr. B. García SÁnCHEZ, La extradición en el ordenamiento interno español, internacional y comunitario, Comares, Granada, 2005, p. 21.

35 Vid. A. B. GreEN, op. cit., pp. 714-715.

Téngase en cuenta que la expresión aut dedere aut iudicare significa literalmente «entregar o juzgar»; ahora bien, el deber de juzgar no se presenta hasta el momento en que el fiscal tiene indicios admisibles suficientes. Sería más acertada la expresión aut dedere aut prosequi (extraditar o procesar). Cfr. Comisión de Derecho Internacional: la obligación de extraditar o juzgar, Informe Amnistía Internacional IOR 40/001/2009, p. 9, nota 13. 
sunto culpable o no [...]. La obligación del Estado Parte se verá cumplida incluso si las autoridades deciden no iniciar el procedimiento» ${ }^{36}$.

Como complemento de las anteriores disposiciones, el art. 8 pretende hacer operativa la extradición con la mayor amplitud posible entre los Estados Partes en la Convención; no obstante, las reservas formuladas por algunos Estados Partes han pretendido mitigar la obligación aut dedere aut iudicare cuando la extradición entrañe un riesgo para los derechos fundamentales del presunto culpable (Portugal) o cuando afecte a nacionales de su país (Mozambique).

Los arts. 4 y 5 de la Convención establecen, respectivamente, un sistema de prevención, información mutua entre los Estados Parte y coordinación en la lucha contra el terrorismo (art. 4), así como la obligación de comunicar acerca de los hechos acontecidos y de intercambiar información sobre el caso (art. 5). En definitiva, lo previsto en ambos artículos es un sistema de cooperación policial entre los Estados Partes en el Convenio. Es significativa a este respecto la reserva formulada por el gobierno suizo que señala: $\ll \mathrm{El}$ Consejo Federal Suizo interpreta los artículos 4 y 5, párrafo 1, del Convenio, significando que Suiza cumplirá las obligaciones contenidas en los mismos en las condiciones establecidas en su legislación interna» que, curiosamente, no ha dado lugar a objeción alguna por ningún otro Estado Parte.

Los arts. 10 y 11 de la Convención establecen las obligaciones, a cargo de los Estados Parte en la misma, de prestarse ayuda en torno a los procedimientos penales abiertos (art. 10) o comunicar al Secretario General de las Naciones Unidas el resultado de las acciones penales contra los presuntos culpables (art. 11). En cumplimiento de esta obligación recogida en el art. 11 destacan las comunicaciones realizadas por Australia el 4 de marzo de 1992 y el 9 de mayo de 1996, siendo el único país que ha suministrado tal información. No obstante, como ya he señalado, dichas informaciones - parciales - se han venido suministrando por al menos veintiún Estados como consta en el Informe del secretario general a la Asamblea General en su $63 .^{\circ}$ periodo de sesiones, en el que se recoge el «Examen de medidas eficaces para mejorar la protección y la seguridad de las misiones y los representantes diplomáticos y consulares» ${ }^{37}$.

${ }^{36}$ Cfr. «Draft articles on the prevention and punishment of crimes against diplomatic agents and other internationally protected persons with commentaries», Yearbook of the International Law Commission, vol. II, A/CN.4/SER.A/1972/Add.1 (1972), p. 318 (traducción de la autora).

37 UN Doc. A/63/121 (27 de octubre de 2008). 


\section{Los tratados de extradición, fundamento y superación del modelo clásico}

La Convención objeto de este comentario, del año 1973, ha sido sobradamente superada por los hechos, aunque el párrafo 2 del art. 10 ampara desarrollos posteriores en el ámbito de la ayuda judicial entre Estados Partes $^{38}$. La posible invocación de los delitos políticos, del principio de libre determinación de los pueblos o de los tratados de asilo hicieron planear sobre el contenido de la Convención serios temores a los que he hecho referencia y que a día de hoy estarían injustificados: la extradición, en la actualidad, se rige por tratado o por ley, pero se basa en el principio de reciprocidad; garantiza el respeto de los derechos fundamentales de los particulares reclamados en los procedimientos de extradición, y constituye un procedimiento reglado para conseguir la aprehensión de los delincuentes, esto es, un acto jurídico en cuanto que está sujeto a requisitos legales, a los que los Estados intervinientes deben someterse, y no un acto político o acto de soberanía sujeto a criterios discrecionales o de oportunidad $^{39}$, o así debería ser. Sobre los tratados de extradición vigentes fundamenta el Convenio la cooperación penal internacional entre los Estados pero, a su vez, grupos de Estados - me estoy refiriendo, en particular, a los Estados miembros de la Unión Europea- han instituido entre sí procedimientos más expeditivos y menos problemáticos que los previstos en los tratados de extradición, es el caso de la Orden de detención y entrega europea ${ }^{40}$ (conocida como «euro orden») ${ }^{41}$, aplicada en España a través de la Ley 3/2003 y cuyo fundamento jurídico — si bien los autores no son unánimes en este punto- ${ }^{42}$ radica en el principio de «reconocimiento

${ }^{38}$ El párrafo 2 del art. 10 de la Convención señala:

«2. Las disposiciones del párrafo 1 del presente artículo no afectarán a las obligaciones de ayuda judicial mutua estipuladas en cualquier otro tratado».

39 Cfr. B. García SÁNChez, op. cit., p. 25.

40 Decisión marco de 13 de junio de 2002, DOCE, núm. L 190, de 18 de julio de 2002.

${ }^{41}$ Entre la múltiple bibliografía sobre la materia, vid. A. Cuerda Riezu, De la extradición a la «euro orden» de detención y entrega. Con un análisis de la doctrina del Tribunal Constitucional español, Centro de Estudios Ramón Areces, Madrid, 2003.

${ }^{42}$ Haciendo referencia a los autores que consideran que la orden europea no es distinta de la tradicional extradición se encuentra B. García Sánchez, que señala las múltiples similitudes que existen entre la euro orden y el procedimiento de extradición. Vid. B. GarCía SÁNCHEZ, op. cit., pp. 418-419, y sobre todo en relación a la oportuna garantía de los derechos fundamentales de las personas objeto de la orden, señala: «Nuestros tribunales tienen que intervenir necesariamente, ya que no sólo se le está privando de libertad al sujeto, sino 
mutuo», esto es, recibida la orden europea por la autoridad judicial competente del Estado ejecutor, éste se compromete a darle curso sin necesidad de verificar la conformidad de la misma a su ordenamiento jurídico interno, por lo que se partiría de la confianza mutua en la estructura y funcionamiento de los respectivos sistemas judiciales penales ${ }^{43}$.

Por otra parte, desde el año 2004, la CDI decidió incluir el tema de la «obligación de extraditar o juzgar (aut dedere aut iudicare)», que había identificado por primera vez como objeto de estudio en 1949, en su programa de trabajo a largo plazo. En 2005 nombró relator especial a Z. Galicki, quien ha presentado a la consideración de la CDI tres informes, observaciones de los gobiernos y un plan de acción ${ }^{44}$. La CDI en 2008 nombró un grupo de trabajo sobre el tema presidido por A. Pellet que, en 2009, propuso un programa general para la consideración de este asunto por parte de la Comisión: fundamento jurídico de la obligación de juzgar o extraditar; ámbito material de la obligación; contenido de la obligación; relación entre la obligación de juzgar o extraditar y otros principios; condiciones para la puesta en marcha de la obligación; realización de la obligación de extraditar o juzgar, y relación de la obligación de extraditar o juzgar con la entrega del presunto culpable a un tribunal internacional competente ${ }^{45}$. En 2010, la CDI constituyó un grupo de trabajo en la materia que, en ausencia de su presidente, sería presidido temporalmente por E. Candioti ${ }^{46}$.

Por su parte, la organización no gubernamental Amnistía Internacional ha seguido muy de cerca la evolución del trabajo de la CDI sobre esta materia, y teniendo en cuenta la débil respuesta de los Estados a la solicitud que hizo la Asamblea General de las Naciones Unidas en $2006^{47}$ para que aquéllos presentaran información sobre tratados internacionales, nor-

que están en juego otros derechos fundamentales, reconocidos en instrumentos internacionales vinculantes para los Estados miembros, que pueden verse lesionados al entregarlo a otro Estado. De ahí que los tribunales españoles deben realizar un examen de la solicitud sobre este extremo» (p. 426).

${ }^{43}$ Cfr. J. Valle-Riestra González-Olaechea, op. cit., p. 54.

44 Según el Informe de la CDI en su 59..$^{\circ}$ periodo de sesiones de 2007, el relator especial presentará, en el periodo comprendido entre 2010 y 2011, un cuarto informe, y si es necesario un quinto, con lo que la CDI concluirá la primera lectura del proyecto de artículos sobre la obligación de extraditar o juzgar. Vid. Asamblea General, Documentos oficiales, $62 .^{\circ}$ periodo de sesiones, suplemento núm. 10 (A/62/10), párrs. 348-368, en http://untreaty.un.org/ilc/ reports/2007/2007report.htm.

${ }^{45}$ Vid. Asamblea General, Documentos Oficiales, $64 .^{\circ}$ periodo de sesiones, suplemento núm. 10 (A/64/10), párrs. 200-204.

46 Vid. International Law Commission, Obligation to extradite or prosecute (aut dedee aut indicare), Summary, en http://www.un.org/law/ilc/.

${ }_{47}$ Res. 61/34 de la Asamblea General, de 4 de diciembre de 2006. 
mativa jurídica interna, práctica judicial y delitos o crímenes sobre el tema, ha elaborado un informe titulado La Comisión de Derecho Internacional: la obligación de extraditar o juzgar (aut dedere aut iudicare) ${ }^{48}$, con tres anexos relativos a los tratados en los que se contiene la obligación de extraditar o juzgar (anexo I), las reservas o declaraciones planteadas a dicha obligación (anexo II), y gráficos relativos al estado de los tratados en los que se contiene la obligación de extraditar o juzgar (anexo III).

La evolución actual de la vida internacional nos debe hacer pensar que la obligación de extraditar o juzgar contenida en los arts. 3, 6, 7 y 8 de la Convención sobre prevención y castigo de delitos contra personas internacionalmente protegidas, incluidos los agentes diplomáticos, que es en esencia bilateral, de Estado a Estado, en el momento actual podría interpretarse también en una tercera dimensión, pues esa obligación podría también verse cumplida en caso de entrega de la persona presuntamente culpable a un tribunal penal internacional ${ }^{49}$.

${ }^{48}$ IOR 40/001/2009.

${ }^{49}$ La triple opción se incluyó en el comentario al art. 9 del Proyecto de Crímenes contra la Paz y la Seguridad de la Humanidad de 1996, que incluye expresamente los crímenes cometidos contra el personal de las Naciones Unidas y el personal asociado (art. 19), que son personas internacionalmente protegidas. Vid. Report of the International Law Comision on the work of its forty-eighth session, pp. 31-32. No obstante, como señala Pignatelli y Meca, ésta es, hoy por hoy, una opción irrealizable ante la Corte Penal Internacional, pues la Conferencia Diplomática de Roma en el Acta Final de la misma, y, a tal efecto, en la Resolución E de su Anexo I, tras reconocer «que los actos terroristas, por quienquiera y dondequiera que sean perpetrados y cualesquiera que sean sus formas, métodos o motivos, constituyen graves crímenes de trascendencia para la comunidad internacional», se manifestó «profundamente alarmada por la persistencia» de este flagelo que constituye una grave amenaza a la paz y la seguridad internacionales, y deploró «que no se haya podido llegar a un acuerdo sobre una definición generalmente aceptable de los crímenes de terrorismo [...] para que quedaran comprendidos en la competencia de la Corte», si bien, tras afirmar «que el Estatuto de la Corte Penal Internacional prevé un mecanismo de revisión que permite extender en el futuro la competencia de la Corte», concluyó recomendando «que en una Conferencia de Revisión, de conformidad con el art. 123 del Estatuto de la Corte Penal Internacional, se examinen los crímenes de terrorismo [...] con miras a llegar a una definición generalmente aceptable y a que queden comprendidos en la lista de crímenes de la competencia de la Corte». Cfr. F. Pignatelli y MeCA, «La posibilidad jurídica de considerar incriminados los actos de terror en el Estatuto de Roma de la Corte Penal Internacional», en M. Pérez GonzÁlez (ed.), Lucha contra el terrorismo. Derecho penal internacional y Derecho internacional humanitario, Tirant lo Blanch, Valencia, en prensa. 


\section{LA ACCIÓN DE LAS NACIONES UNIDAS EN LA LUCHA CONTRA LOS ATENTADOS TERRORISTAS COMETIDOS CONTRA PERSONAS INTERNACIONALMENTE PROTEGIDAS: OTRO EJEMPLO DE SUPERACIÓN DEL MODELO CONVENCIONAL. ESPECIAL REFERENCIA AL TRIBUNAL ESPECIAL PARA EL LÍBANO}

Como ya he señalado, los atentados contra personas internacionalmente protegidas, frecuentes en los años setenta y ochenta del pasado siglo, han dado paso a formas renovadas - en todo caso terriblemente cruentas y, en múltiples ocasiones, masivas por los enormes daños personales y materiales que ocasionan - de ejercicio del terrorismo internacional. Así, los distintos y principales órganos de la Organización de las Naciones Unidas, si bien se han venido ocupando del fenómeno terrorista desde tiempos pasados, su actividad se ha visto multiplicada exponencialmente a partir de los atentados del 11 de septiembre de 2001. Sin ánimo de hacer un recuento pormenorizado de todas las actividades desarrolladas por los órganos de la organización mundial, sí me parece conveniente señalar algunas de las realizadas por los órganos principales:

- La Asamblea General de las Naciones Unidas creó en 1972 el Comité sobre terrorismo internacional, aunque no obtuvo mucho éxito, adoptando entonces la estrategia de los «acuerdos sectoriales» entre los que se cuenta el convenio objeto de este análisis ${ }^{50}$. En la actualidad traba-

50 1. Convenio sobre las infracciones y ciertos otros actos cometidos a bordo de las aeronaves, 1963.

2. Convenio para la represión del apoderamiento ilícito de aeronaves, 1970.

3. Convenio para la represión de actos ilícitos contra la seguridad de la aviación civil, 1971.

4. Convención sobre la prevención y el castigo de delitos contra personas internacionalmente protegidas, inclusive los agentes diplomáticos, 1973.

5. Convención internacional contra la toma de rehenes, 1979.

6. Convención sobre la protección física de los materiales nucleares, 1980.

7. Protocolo para la represión de actos ilícitos de violencia en los aeropuertos que presten servicio a la aviación civil internacional, 1988.

8. Convenio para la represión de actos ilícitos contra la seguridad de la navegación marítima, 1988.

9. Protocolo para la represión de actos ilícitos contra la seguridad de las plataformas fijas emplazadas en la plataforma continental, 1988

10. Convenio sobre la marcación de explosivos plásticos para los fines de detección, 1991.

11. Convenio internacional para la represión de los atentados terroristas cometidos con bombas, 1997. 
ja en la elaboración de un convenio global sobre la lucha contra el terrorismo internacional que ve retrasada su adopción por el intenso debate y por las diferencias existentes en torno a la definición del fenómeno ${ }^{51}$. En 2006 fue aprobada por la Asamblea General (Resolución 60/288) la Estrategia global de las Naciones Unidas contra el terrorismo, que se apoya en el informe del Secretario General de la organización titulado «Unidos contra el terrorismo: recomendaciones para una estrategia mundial de lucha contra el terrorismo» y que condena de manera sistemática, inequívoca y firme el terrorismo en todas sus formas y manifestaciones, independientemente de quién lo cometa, en dónde y con qué propósitos, pues constituye una amenaza para la paz y seguridad internacionales, y en su anexo contiene una serie de medidas para hacer frente a las condiciones que propician la propagación del terrorismo, para prevenir y combatir el terrorismo, para aumentar la capacidad de los Estados para prevenir el fenómeno y para asegurar el respeto de los derechos humanos ${ }^{52}$.

- No ha sido la Asamblea General el único órgano dedicado al terrorismo internacional: el Consejo de Seguridad, desde los años noventa ${ }^{53}$, pero especialmente a partir de los atentados del 11 de septiembre de 2001, ha incorporado en el concepto de «amenaza a la paz» el terrorismo sin calificativos que lo acompañen (esto es, «internacional» o «interno», matiz que aparecía en la Resolución 1.269, aunque fuera para condenar ambos tipos), desarrollando una amplia labor en tres frentes que superan la mera asociación del terrorismo con el concepto de «amenaza a la paz» [Reso-

12. Convenio internacional para la represión de la financiación del terrorismo, 1999.

13. Convenio internacional para la represión de los actos de terrorismo nuclear, 2005.

51 Vid. M. Aвad CAstelos, «Una historia interminable: a vueltas con la definición de terrorismo a través del enfoque del Derecho internacional», en M. PÉrEz GonzÁLEz (ed.), Lucha contra el terrorismo. Derecho penal internacional y Derecho internacional bumanitario, Tirant lo Blanch, Valencia, en prensa.

52 En aplicación de dicha Estrategia, el secretario general Ban Ki-Moon elaboró un informe sobre la aplicación de la Estrategia por las Naciones Unidas (septiembre de 2008), convocó (9 de septiembre de 2008) el Simposio sobre el apoyo a las víctimas del terrorismo y, para el segundo examen de la aplicación de la mencionada Estrategia (8 de septiembre de 2010), dio a conocer el segundo informe sobre las actividades de las Naciones Unidas en aplicación de la Estrategia global contra el terrorismo.

53 El Consejo de Seguridad adopta desde los años noventa del pasado siglo sanciones contra los Estados vinculados con actos de terrorismo: la Jamahiriya Árabe Libia (1992), Sudán (1996) y los talibanes (1999), ampliadas para incluir a Al-Qaida en 2000 en la Resolución 1.333. También antes de los atentados del 11 de septiembre de 2001, el Consejo de Seguridad había establecido el Comité 1.267, encargado de supervisar la aplicación de las sanciones contra los talibanes (y posteriormente Al-Qaida a partir de 2000), establecido en 1999 (Resolución 1.267). 
lución 1.368 (2001)]: 1) a través de las sanciones; 2) a través de las declaraciones de carácter general y 3 ) desarrollando una labor cuasi legislativa [Resoluciones $1.373(2001)^{54}, 1.540(2004)^{55}, 1.535(2004), 1.566(2004)^{56}$ y 1.624 (2005)], actividad en su conjunto no exenta de polémica.

En el marco de la amplia, y criticada por ello, actividad desplegada por el Consejo de Seguridad de las Naciones Unidas en relación con el terrorismo como amenaza a la paz y a la seguridad internacionales, y referido asimismo al objeto del Convenio sobre prevención y castigo de delitos contra personas internacionalmente protegidas, es de mencionar el atentado terrorista ocurrido en febrero del año 2005 en Beirut, por la explosión de un coche bomba, que costaría la vida al que fuera en dos ocasiones primer ministro del Líbano Rafiq Hariri, junto con otras veintidós personas. Es éste un claro supuesto de aplicación del Convenio que, asimismo, pone de manifiesto la superación del modelo en él previsto. Ello es así debido a que, aun siendo partes en el Convenio tanto Líbano como Siria -Estado este último presuntamente implicado en el magnicidio, según los informes-, dicho tratado no se ha invocado como recurso al que acudir para resolver el crimen, sino que se ha seguido un camino bien distinto: en efecto, el 13 de diciembre de 2005, el gobierno de la República Libanesa pidió a las Naciones Unidas que establecieran un tribunal de carácter internacional para enjuiciar a todos los presuntos responsables del atentando que tuvo lugar el 14 de febrero de 2005 en Beirut y causó la muerte del ex primer ministro Libanés Rafiq Hariri y de otras veintidós personas. Con arreglo a la Resolución 1.664 (2006) del Consejo de Seguridad, las Naciones Unidas y la República Libanesa negociaron un acuerdo sobre el establecimiento de un Tribunal Especial para el Líbano. Una vez aprobada la Resolución 1.757 (2007) del Consejo de Seguridad, de 30 de mayo de 2007, las disposiciones del documento anexo a ella, incluido el Estatuto del Tribunal Especial que figuraba como apéndice, entraron en vigor el 10 de junio de 2007. El man-

${ }^{54}$ Donde se reseña el corpus legal de la prevención en la lucha contra el terrorismo, así como el derecho inmanente a la legítima defensa, y establece medidas obligatorias (de tipo financiero y relativas a la cooperación entre Estados) y recomendaciones.

55 Creación de un Comité contra el terrorismo encargado de vigilar la aplicación de la Resolución 1.373.

${ }^{56}$ La Resolución 1.566 (2004) estableció un grupo de trabajo 1.566 encargado de presentar recomendaciones sobre las medidas prácticas contra las personas, los grupos y las entidades involucrados en actividades terroristas. Cfr. P. SÁenz de SANTAmaría, «Collective Measures to Counter International Terrorism», en P. A. FERnández SÁnchez (ed.), International Legal Dimension of Terrorism, Leiden-Boston, Martinus Nijhoff Publishers, 2009, pp. 95-105. 
dato del Tribunal Especial para el Líbano es enjuiciar a los responsables del atentado de 14 de febrero de 2005 que causó la muerte del ex primer ministro Rafiq Hariri y provocó la muerte o lesiones a otras personas. Las Naciones Unidas y el gobierno del Líbano acordaron que el Tribunal tendría una composición mixta, con la participación de magistrados libaneses e internacionales y un fiscal internacional. Las normas de justicia del Tribunal, incluidas las garantías procesales, se basarán en las más altas normas internacionales de justicia penal que se aplican en los demás tribunales internacionales. El Tribunal Especial aplica la ley nacional, ya que el Estatuto dispone que serán de aplicación las disposiciones del Código Penal del Líbano relativas al enjuiciamiento y castigo de los actos de terrorismo y los crímenes y delitos contra la vida y la integridad personal, entre otros ${ }^{57}$.

Este supuesto práctico revela, en todo caso, que la actividad de los órganos de las Naciones Unidas, concretamente del Consejo de Seguridad, en el marco del Capítulo VII de la Carta de las Naciones Unidas, desborda o supera con creces el modelo convencional, encorsetado por las reglas técnicas de participación en el tratado y por el juego de las reservas y las posibles objeciones a las mismas que hacen del Derecho internacional un ordenamiento eminentemente relativo.

\section{CONCLUSIONES}

La Convención sobre prevención y castigo de delitos contra personas internacionalmente protegidas, incluidos los agentes diplomáticos, de 1973, objeto de este estudio, constituye un meritorio esfuerzo de codificación de las reglas internacionales penales y procesales que hacen posible que las personas presuntamente culpables de la comisión de algún atentado violento contra los agentes protegidos no queden impunes, estableciendo para ello un sistema que se basa en el viejo, pero no por ello caduco, adagio, aut dedere aut indicare a cargo de los Estados Partes en el Convenio. Es, por ello, complemento necesario de las normas más elementales (inviolabilidad personal y de los locales e inmunidad de jurisdicción) del Derecho diplomático y consular, pues aquéllas adquieren efectividad práctica gracias a este tratado.

Aunque la razón de ser de este instrumento no ha perdido un ápice de actualidad, sino todo lo contrario - como lo prueban los trabajos desa-

${ }^{77}$ http://www.un.org/spanish/News/focus/tslibano/factsheet.shtml. 
rrollados sobre el tema en la Sexta Comisión de la Asamblea General de las Naciones Unidas y los informes periódicos del secretario general de la organización ${ }^{58}$, así como el trabajo de la CDI, aún inconcluso, sobre la regla aut dedere aut indicare ${ }^{59}$, o la labor desarrollada por organizaciones no gubernamentales de prestigio, como Amnistía Internacional—, sí que se puede decir que, por una parte, no ha servido para prevenir o limitar los atentados contra personas internacionalmente protegidas $\mathrm{y}$, por otra, ha resultado en cierta medida superada por los acontecimientos que han tenido lugar desde su adopción, hace casi cuarenta años. En efecto, los atentados terroristas han dejado de escoger como blanco predilecto a las personas internacionalmente protegidas, decantándose, en contrapartida, por actos indiscriminados dirigidos contra amplios sectores de la población, normalmente civil. Un hecho relevante para la aplicación del Convenio, como sería la comisión en 2005 del atentado con bomba contra una persona internacionalmente protegida —el ex primer ministro libanés Rafiq Hariri-, no sólo colocó en primer plano importantes principios de Derecho internacional aparentemente conculcados -injerencia en los asuntos internos de un Estado extranjero, posible responsabilidad internacional del Estado en la comisión del atentado terrorista, entre otros-, sino que también reveló la ineficacia del Convenio sobre represión y castigo de delitos contra personas internacionalmente protegidas, incluidos los agentes diplomáticos, cuando está en juego el equilibrio de una frágil región, como Oriente Medio, y el propio mantenimiento de la paz y la seguridad internacionales, lo que exigió una acción de parte del Consejo de Seguridad de las Naciones Unidas, creando una Comisión de investigación y un Tribunal mixto al efecto que aplica el Derecho Penal libanés.

58 Vid., sobre estos desarrollos, la página web de la Sexta Comisión, disponible en http://www.un.org/spanish/aboutun/organs/ga/63/sixth/info.shtml.

59 Vid. sobre los trabajos en curso sobre el tema, en la CDI, http://www.un.org/law/ilc/. 